\title{
Reação de genótipos de meloeiro a Myrothecium
}

\author{
Marissônia A Noronha²; Sami J Michereff ${ }^{2}$; Maria S Xavier Filha²; Priscilla A A Moreira ${ }^{2}$; Ailton Reis ${ }^{3}$; \\ Rui Sales Júnior ${ }^{4}$
}

${ }^{2}$ UFRPE-Dep ${ }^{\text {to }}$. Agronomia, Av. Dom Manoel de Medeiros, s/nº, 52171-900 Recife-PE; ${ }^{3}$ Embrapa Hortaliças, C. Postal 218 , 70359-970 Brasília-DF; ${ }^{4}$ UFERSA-Dep ${ }^{\text {to }}$. Ciências Vegetais, C. Postal 137, 59600-970 Mossoró-RN; *Bolsista CNPq; E-mail: sami@ufrpe.br

\section{RESUMO}

A expansão da cultura do meloeiro (Cucumis melo L.) no Nordeste brasileiro tem favorecido a ocorrência de doenças como o cancro-de-mirotécio, causado pelo fungo Myrothecium roridum. Visando selecionar genótipos com potencial de utilização nos programas de melhoramento e/ou no manejo integrado da doença, foram avaliados 150 genótipos de meloeiro. Plantas com 22 dias de idade, desenvolvidas em casa de vegetação, foram feridas no colo e inoculadas com uma suspensão do patógeno $\left(3 \times 10^{6}\right.$ conídios $\left./ \mathrm{ml}\right)$. As avaliações foram realizadas diariamente, até seis dias após a retirada da câmara úmida, com o auxílio de uma escala descritiva de notas de 0 a 4. Com os dados da última avaliação, os genótipos foram distribuídos em cinco classes de reação à doença. Nenhum genótipo foi imune ou altamente resistente ao patógeno, enquanto $26,7 \%$ foram medianamente resistentes (MR) e 73,3\% foram suscetíveis (S) ou altamente suscetíveis (AS). Esses resultados evidenciam a dificuldade na obtenção de fontes com elevados níveis de resistência a $M$. roridum. Os grupos Cantaloupe, Charentais, Gália e 'Indefinido' apresentaram a maior freqüência de genótipos com a reação MR e a menor freqüência de genótipos AS. A maioria dos genótipos dos grupos Valenciano Verde $(66,7 \%)$, Cantaloupe $(57,4 \%)$, Gália (60,0\%) e 'Indefinido' (53,8\%) foram S. Os genótipos 'PI 420149', 'Caroline', 'A3', 'Chilton' e 'PS-1 Pele de Sapo' apresentaram os menores valores de severidade final da doença e mostraram-se promissoras fontes de resistência ao patógeno e devem ser preferidos sob condições favoráveis à doença.

Palavras-chave: Cucumis melo, cancro-de-mirotécio, recursos genéticos.

\section{ABSTRACT}

\section{Reaction of melon genotypes to Myrothecium roridum}

The expansion of the melon (Cucumis melo L.) fields in the Brazilian Northeast favored the occurrence of diseases such as the Myrothecium stem canker caused by the fungus Myrothecium roridum. In order to select genotypes with potential use in genetic breeding programs and in integrated disease management, 150 melon genotypes were evaluated. Twenty-two day old melon plants cultivated under greenhouse conditions were pierced in the crown and inoculated with a pathogen suspension $\left(3 \times 10^{6}\right.$ conidia $\left./ \mathrm{ml}\right)$. The evaluations were done daily, with the aid of a descriptive scale varying from 0 to 4, until six days after the moist chamber had been removed. The genotypes were distributed in five classes of disease reaction using data of the last evaluation. None of the genotypes were immune or highly resistant to the disease, $26.7 \%$ were intermediate resistant (IR) and $73.3 \%$ were susceptible (S) or highly susceptible (HS). These results illustrate the difficulties in obtaining genetic sources with high levels of resistance to $M$. roridum. The groups Cantaloupe, Charentais, Galia and Undefined showed the largest frequency of genotypes with IR reaction and the smallest frequency of HS genotypes. Most of the genotypes of the groups Yellow Valencian (66.7\%), Cantaloupe $(57.4 \%)$, Galia (60.0\%) and 'Undefined' (53.8\%) were susceptible. The genotypes 'PL 420149', 'Caroline', 'A3', 'Chilton' and 'PS-1 Pele de Sapo' showed the lowest values of disease severity and are promising resistance sources to the pathogen, and should be preferred in commercial fields subject to the disease.

Keywords: Cucumis melo, Myrothecium stem canker, genetic resources.

\section{(Recebido para publicação em 12 de junho de 2006; aceito em 18 de dezembro de 2006)}

A cultura do meloeiro (Cucumis melo L.) tem grande expressão econômica no Brasil, onde são cultivados cerca de 16.300 ha e produzidos $349.500 \mathrm{t}$ (FNP, 2006). No ano de 2005, o melão se destacou dentre as exportações brasileiras como a segunda fruta fresca com maior remuneração (US\$ 91.478.533,00), sendo superado apenas pela uva (US\$ 107.276.014,00) (IBRAF, 2006). O Nordeste brasileiro é responsável por aproximadamente $95 \%$ da produção nacional de melão, destacandose os estados do Rio Grande do Norte e do Ceará, com cerca de $55 \%$ e $28 \%$ da produção brasileira, respectivamente (FNP, 2006). As principais áreas produtoras nesses estados localizam-se na região semi-árida e se concentram nos agropólos Mossoró/Assu e Baixo Jaguaribe (Negreiros et al., 2005).

O meloeiro apresenta excelente adaptação às condições edafo-climáticas predominantes na região Nordeste do Brasil; no entanto, devido ao seu cultivo intensivo, inúmeros fatores têm contribuído para a queda da produtividade e da qualidade dos frutos, entre os quais se destaca a ocorrência de doenças (Viana et al., 2001). Dentre estas, o cancro-de-mirotécio, causado pelo fungo Myrothecium roridum Tode ex Fries, foi detectado pela primeira vez no Brasil em 1991, em Mossoró (Silva et al., 1996) e, desde então, vem ocorrendo com freqüência nos plantios da região.

Os sintomas do cancro-de-mirotécio ocorrem em várias partes do meloeiro, porém são mais comuns próximos ao colo e se caracterizam por lesões alongadas, necróticas, que se tornam deprimidas, com a posterior formação de estruturas de frutificação do fungo (esporodóquios) de coloração verdeoliva, que são abundantes e visíveis a

${ }^{1}$ Parte da tese de Doutorado da primeira autora, apresentada à Universidade Federal Rural de Pernambuco, para obtenção do título de Doutor em Fitopatologia 
olho nu. Quando as lesões no colo surgem na presença de alta umidade, ocorre a morte rápida da planta (Bruton, 1996).

A resposta do meloeiro a patógenos habitantes do solo pode ser influenciada pelo nível de resistência, densidade do inóculo e virulência do patógeno, e pelas condições ambientais (Bruton, 1998). Como M. roridum é um habitante do solo com ampla gama de hospedeiros (Fitton \& Holliday, 1998), o seu controle é extremamente difícil (Bruton, 1996), motivo pelo qual a utilização de cultivares resistentes constitui uma medida estratégica no manejo integrado da doença.

Apesar da importância do cancro-demirotécio, existem poucos estudos sobre avaliação da resistência em meloeiro a $M$. roridum. No Brasil, foram realizados apenas dois trabalhos com esse objetivo, sendo avaliados somente dez (Silva et al., 1993) e seis (Lima et al., 1997) genótipos. Nos Estados Unidos, foi avaliada a reação de 50 genótipos utilizando folhas destacadas (Kuti et al., 1987). Contudo, é necessário ressaltar que nas áreas produtoras do Nordeste brasileiro são raros os sintomas foliares da doença. Em todos esses trabalhos foi constatada diferença entre os genótipos quando inoculados com $M$. roridum, mas não foi efetuada uma classificação quanto aos níveis de resistência. Desta forma, visando subsidiar futuros programas de melhoramento genético na cultura do meloeiro, bem como selecionar cultivares com potencial de utilização nos programas de melhoramento ou no manejo integrado do cancro-demirotécio, este trabalho teve como objetivo avaliar a resistência de 150 genótipos de meloeiro a $M$. roridum.

\section{MATERIAL E MÉTODOS}

A avaliação da resistência foi realizada em casa de vegetação, na Universidade Federal Rural de Pernambuco, em Recife. Uma coleção de 150 genótipos comerciais de meloeiro, oriundos do banco de germoplasma da Embrapa Hortaliças (Brasília-DF) e de empresas produtoras de sementes, foi avaliada em relação a um isolado de $M$. roridum (LE-609). A coleção de genótipos compreendeu oito grupos comerciais de melão: Valenciano Amare- lo (34 genótipos), Valenciano Verde (3 genótipos), Cantaloupe (47 genótipos), Honeydew (9 genótipos), Gália (15 genótipos), Charentais (20 genótipos), Pele de Sapo (9 genótipos) e 'Indefinido' (13 genótipos que constituem uma mistura de híbridos). $\mathrm{O}$ isolado de $M$. roridum (LE-609) foi obtido de planta de meloeiro da cultivar Gold Mine com sintoma de cancro no colo, coletada em Mossoró. Esse isolado foi selecionado com base em análise preliminar da variabilidade de populações do patógeno oriundas de meloeiros cultivados no Agropólo Mossoró/Assu (Noronha et al., 2006). Os conídios do fungo foram obtidos de culturas esporulantes com 14 dias de idade, crescidas em meio de cultura batata-dextrose-ágar (BDA) a 25 \pm 2 ${ }^{\circ} \mathrm{C}$, sob alternância luminosa (12 h claro/12 h escuro). A inoculação foi efetuada em plantas com 22 dias de idade mantidas em casa de vegetação, cultivadas em solo franco arenoso $(\mathrm{pH}=6,4$; $\mathrm{N}$ : $1.030 \mathrm{ppm} ; \mathrm{P}=3 \mathrm{mg} / \mathrm{dm}^{3} ; \mathrm{K}=0,14$ $\mathrm{cmol}_{\mathrm{c}} / \mathrm{dm}^{3} ; \mathrm{Al}=: 1,40 \mathrm{cmol} / \mathrm{dm}^{3}$; $\mathrm{Ca}+\mathrm{Mg}=0,80 \mathrm{cmol} / \mathrm{dm}^{3}$ ) esterilizado com brometo de metila (Bromex ${ }^{\circledR}$ ) e acondicionado em vasos plásticos $(4 \mathrm{~kg}$ de capacidade). Inicialmente, as plantas foram feridas no colo, a cerca de $10 \mathrm{~mm}$ da superfície do solo, com o auxílio de uma almofada com dois alfinetes entomológicos eqüidistantes em $10 \mathrm{~mm}$, à profundidade de $2 \mathrm{~mm}$. Em seguida, cada planta foi inoculada com o patógeno pela atomização de $5 \mathrm{ml}$ da suspensão de conídios $\left(3 \times 10^{6}\right.$ conídios $/ \mathrm{ml}$ ) suplementada com Tween $20(0,1 \%)$, com o auxílio de atomizador DeVilbiss (Noronha \& Michereff, 2006). Cinco plantas de cada genótipo foram feridas e atomizadas com água destilada esterilizada, sendo utilizadas como testemunha. Após a inoculação, as plantas foram mantidas em câmara úmida por 36 horas, constituída de sacos de polietileno umedecidos, e posteriormente em condições normais da casa de vegetação. As parcelas experimentais, constituídas por um vaso com seis plantas cada, foram replicadas no tempo em quatro vezes, em um delineamento de blocos ao acaso.

A reação das plantas ao cancro-demirotécio foi avaliada aos seis dias após a retirada da câmara úmida, com o auxílio de uma escala descritiva de notas de 0 a 4 , onde: $0=$ sem sintomas; $1=1 \mathrm{e}$ sões no caule de 0,1 a $6,9 \mathrm{~mm} ; 2=1 \mathrm{e}-$ sões no caule > $7 \mathrm{~mm}$, sem esporodóquios; $3=$ lesões no caule $>7$ mm, com esporodóquios; e 4= morte da planta. Foi calculada a reação média de cada genótipo pela soma das notas de cada planta e divisão pelo número total de plantas avaliadas. Esse valor foi utilizado para discriminar os genótipos em cinco classes de reação: $0=$ semelhante à imune $(\mathrm{SI}) ; 0,1-1,0=$ altamente resistente $(\mathrm{AR}) ; 1,1-2,0=$ medianamente resistente (MR); 2,1-3,0= suscetível (SU); $3,1-4,0=$ altamente suscetível (AS). O índice de severidade final (SVF) da doença em cada vaso foi calculado de acordo com McKinney (1923), pela expressão: $\mathrm{SVF}=[\mathrm{S}$ (grau da escala $\mathrm{x}$ freqüência)/(número total de unidades $\mathrm{x}$ grau máximo da escala)]x100, utilizando-se os dados obtidos com a escala de notas. Os dados de SVF foram transformados em raiz $(x+0,5)$ e submetidos à análise de variância, sendo as médias dos genótipos comparadas pelo teste de Scott-Knott $(\mathrm{P}=0,05)$.

Durante o período de execução do experimento, a temperatura na casa-devegetação foi de $28,3 \pm 3,2^{\circ} \mathrm{C}$ e a umidade relativa de $73,4 \pm 6,1 \%$.

\section{RESULTADOS E DISCUSSÃO}

Nenhum genótipo de meloeiro apresentou reação semelhante a imunidade ou alta resistência a $M$. roridum, enquanto $26,7 \%$ foram medianamente resistentes, $51,3 \%$ foram suscetíveis e 22,0\% altamente suscetíveis (Tabela 1). Esses resultados evidenciam a dificuldade na obtenção de fontes com elevados níveis de resistência a $M$. roridum em germoplasma de meloeiro, provavelmente devido ao processo de patogênese exercido, pois durante a infecção ocorre a formação de estruturas somáticas produtoras de enzimas, metabólicos tóxicos e substâncias que induzem a síntese de etileno no hospedeiro (Domsch et al., 1980), provocando o aumento da atividade metabólica das células e a maior predisposição à infecção, mesmo em tecidos imaturos.

Quando consideradas as reações dentro dos grupos comerciais de melão (Figura 1), 100\% dos genótipos do grupo Valenciano Verde, $88 \%$ do grupo 
Tabela 1. Reação de genótipos de meloeiro a Myrothecium roridum sob condições de casa de vegetação. Recife, UFRPE, 2005.

\begin{tabular}{|c|c|c|c|}
\hline Classe & Genótipos & Nota & $\begin{array}{c}\text { Severidade } \\
\text { final }(\%)^{4}\end{array}$ \\
\hline $\begin{array}{l}\text { Medianamente } \\
\text { resistente }\end{array}$ & $\begin{array}{l}\text { Pl 420149, Caroline, A3, Chilton, PS-1 Pele de Sapo, Amarilla Canário, Cinco, } \\
\text { Doublon, A2, Melão Cabloco RN, Kallósemjén, Nansho Earls, Delicious 51, Heves, } \\
\text { Hegykô, Lutetia, Irene, 193258, Nyíribrony, Taktaharkány, 193249, M61G6, Magnum, } \\
\text { Tesoro Dulce, Aroma F1, Super Doce, Burpee Hybrid, Polidor II, Ambrosia Hybrid, } \\
\text { Honey Pac, PS } 30595 \text {, Reliant, Navajo, PX } 3810628 \text {, Carillon, Early Down Rockm, } \\
\text { Fleuron, Ananás, Colima e Galileo }\end{array}$ & $1,1-2,0$ & $27,1-51,0$ \\
\hline Suscetível & $\begin{array}{l}\text { M89CH4, Vienna, Roadside, Torreon, Gallardo, Valleypac, Athenas, Touchdown, } \\
\text { Laguna, M69CH2, Szirma, RML 5001, PS-2 Pele de Sapo, Gold Star, F1 Pancha, } \\
\text { H019, Super Sprint, Deltex, Vector F1, Pacstart, Pulsar, Mission, XPH 6006, Edisto 47, } \\
\text { Aroma F1, Vereda, Gaúcho, Nilo, Neve, Hales Best Jumbo, Rockm. Gulfcoast, Zeus, } \\
\text { Pusztadobos, Super Market, AF-646, Catucho, Tápiószele, Turkeve, Gulf Coast, PX } \\
\text { 3703001, Perlita, RS 308095, Marygold 735, Sea Bolt, M63A1, Famosa, PS 2264, } \\
\text { Dolidor F1, TM 001-F1, Yupi, Charentais Fom1, AF-1805, USDA 161375, Charentais - } \\
\text { T, Rockmelon Planters, EX 54756, B 66.5, Gold Mine, Verde Comprido, Valencia, AF- } \\
\text { 682, Dolidor F1, Eros, Galia Canário, F1 Pharo, TR 66005, W6, M53A2, Madras, } \\
\text { Shavit Hybrid, Glover, Valenciano Eliptico, Billeberga, RML 5006, Gold - 264, Golda } \\
\text { e Acclaim }\end{array}$ & $2,1-3,0$ & $52,1-76,0$ \\
\hline \multirow[t]{2}{*}{$\begin{array}{l}\text { Altamente } \\
\text { suscetível }\end{array}$} & $\begin{array}{l}\text { WMR - 29, Melão Trevo, Pinonet, Taiwan \# 7, A1, Hy-Mark, Trueno, Amarelo Polpa } \\
\text { Branca, Honey Cup, Rochedo, M63A17, Gold King, Pele de Sapo, Legend F1, Trusty } \\
\text { LSL, Dikie Jumbo, F1 Helios, Gold Pride, PRS 3703001, Cristobal, Muskmelon } \\
\text { 18072, Yellow Queen, Orange Flesh, Top Mark, TM 002-f1, Yeloow King, Valenciano } \\
\text { Redondo, Marigold 871, Honey Dew, Amarelo, Eldorado, Honey Dew Green Flesh, } \\
\text { Napoletano }\end{array}$ & $3,1--4,0$ & $77,1-100$ \\
\hline & C.V. (\%) & & 8,6 \\
\hline
\end{tabular}

${ }^{1}$ Grupos comerciais: VA= Valenciano Amarelo; $\mathrm{VV}=$ Valenciano Verde; $\mathrm{CA}=$ Cantaloupe; $\mathrm{HD}=$ Honeydew; $\mathrm{GA}=\mathrm{Gália}$; $\mathrm{CH}=\mathrm{Charentais}$; PS= Pele de Sapo; IN='Indefinido'; ${ }^{2}$ Classe de reação da doença conforme escala de notas de 0 a 4, onde: $0=$ sem sintomas; $1=$ lesões no caule de 0,1 a $6,9 \mathrm{~mm}$; $2=$ lesões no caule $>7 \mathrm{~mm}$, sem esporodóquios; $3=$ lesões no caule $>7 \mathrm{~mm}$, com esporodóquios; e 4= morte da planta; ${ }^{3}$ Reação da doença: $0=$ semelhante à imune (SI); 0,1-1,0= altamente resistente (AR); 1,1-2,0= medianamente resistente (MR); 2,13,0= suscetível (SU); 3,1-4,0= altamente suscetível (AS); ${ }^{4}$ Severidade final da doença, calculada pelo índice de Mckinney (1923), com a utilização das frequiências de classes de doença considerando escala de notas de a 0 a $4 ;{ }^{5}$ Médias originais de quatro repetições. Para efeito de análise, os dados foram transformados em $\sqrt{x+0.5}$. Médias seguidas pela mesma letra não diferem significativamente entre si pelo teste de Scott-Knott $(\mathrm{P}=0,05)$.

Valenciano Amarelo, $72 \%$ do grupo Cantaloupe, $67 \%$ do grupo Galia e $62 \%$ do grupo 'Indefinido' foram suscetíveis ou altamente suscetíveis. Por outro lado, no grupo Charentais a maioria $(56 \%)$ dos genótipos foi medianamente resistente e somente $5 \%$ foram altamente suscetíveis. Mais de 30\% dos genótipos de Gália e 'Indefinido' foram medianamente resistentes. Nos grupos Honeydew e Pele de Sapo, somente 11\% dos genótipos foram medianamente resistentes, enquanto que $44 \%$ foram suscetíveis e altamente suscetíveis.

Pela análise de agrupamento de Scott-Knott, foram distinguidos cinco grupos de genótipos de meloeiro quanto aos níveis de SVF, destacando-se 'PI 420149', 'Caroline', 'A3', 'Chilton' e 'PS-1 Pele de Sapo' com os menores valores, que diferiram significativamente $(\mathrm{P}=0,05)$ dos demais grupos de genótipos (Tabela 1). Esses genótipos pertencem aos grupos comerciais
Valenciano Amarelo ('A3'), Cantaloupe ('Chilton'), Pele de Sapo ('PS-1 Pele de Sapo') e 'Indefinido' ('PI 420149' e 'Caroline') e constituem promissoras fontes de resistência a $M$. roridum em programas de melhoramento de meloeiro. Em estudos realizados previamente no Brasil, Silva et al. (1993) constataram que um genótipo do grupo Pele de Sapo ('Pele de Sapo') e outro do grupo Valenciano Amarelo ('Eldorado x Douradinho') mostraram-se promissoras fontes de resistência a $M$. roridum, enquanto Lima et al. (1997) verificaram que as cultivares 'Amarelo Ouro' e 'Pingo de Mel' foram as mais suscetíveis ao patógeno, enquanto 'Imperial' apresentou o melhor nível de resistência, todos pertencentes ao grupo Valenciano Amarelo.

É importante salientar que as cultivares de meloeiro em uso, em sua quase totalidade, foram desenvolvidas nas condições do Hemisfério Norte, com dias longos, menor amplitude térmica entre os dias e noites, com ciclos de cultivo longos entre 100 e 120 dias. Nas principais regiões produtoras brasileiras, as cultivares importadas se tornam precoces, com ciclos entre 60 e 70 dias e problemas de adaptação, resultando em menor produtividade e frutos de qualidade inferior. Em adição, essas cultivares não apresentam, resistência às doenças importantes para a cultura no país, o que contribui para a elevação no custo de produção devido à maior utilização de agrotóxicos (Costa \& Silva, 2002).

Entre os seis genótipos mais plantados nos agropólos Mossoró/Assu e Baixo Jaguaribe, que totalizam cerca de 90\% da área cultivada (Nunes et al., 2004), três apresentaram reação de suscetibilidade ('AF-646', 'AF-682' e 'Gold Mine') e outros três foram altamente suscetíveis ('Gold Pride', 'Orange Flesh' e 'Rochedo'), indicando que em surtos epidêmicos de cancrode-mirotécio os prejuízos poderão ser 


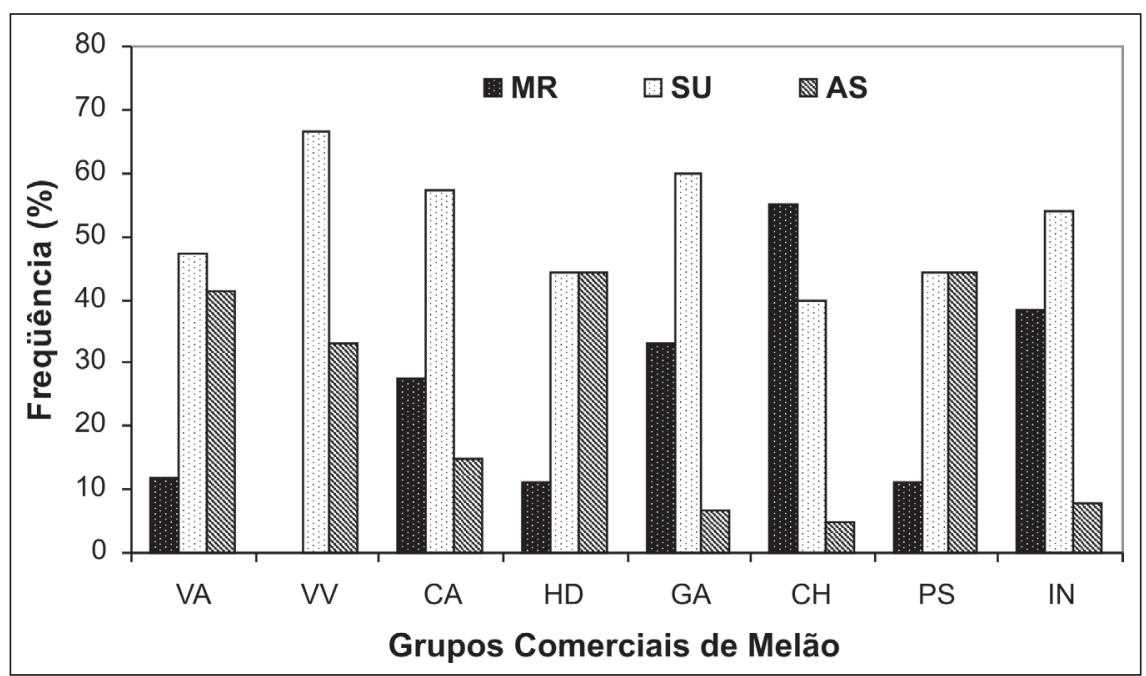

Figura 1. Frequiência (\%) de genótipos de meloeiro dos grupos comerciais (VA= Valenciano Amarelo; $\mathrm{VV}=$ Valenciano Verde; $\mathrm{CA}$ - Cantaloupe; $\mathrm{HD}=$ Honeydew: $\mathrm{GA}=\mathrm{Gália} ; \mathrm{CH}=$ Charentais; PS= Pele de Sapo e IN= 'Indefinido') apresentando os níveis de resistência ( $\mathrm{MR}=$ medianamente resistente; $\mathrm{SU}=$ suscetível e $\mathrm{AS}=$ altamente suscetível) a Myrothecium roridum. Recife, UFRPE, 2005.

elevados, pois nenhum dos genótipos apresentou nível aceitável de resistência ao patógeno.

Os cinco genótipos de meloeiro detectados nesse estudo como fontes promissoras de resistência a $M$. roridum deverão ser investigados quanto à estabilidade da resistência a vários isolados e densidades de inóculo do patógeno, e quanto a herança da resistência. É necessário enfatizar que a resistência utilizada isoladamente não é suficiente para o adequado controle das doenças radiculares do meloeiro (Bruton, 1998), havendo necessidade da adoção de estratégias complementares de manejo para maximizar a durabilidade da resistência a $M$. roridum, dentre as quais se destacam o uso das rotações de áreas de cultivo, de culturas e de genótipos de meloeiro, bem como evitar injúrias nas plantas durante os tratos culturais e promover a destruição dos restos culturais.

\section{AGRADECIMENTOS}

Os autores expressam seus agradecimentos ao CNPq pelo financiamento (processo ${ }^{\circ}$. 620111/04-6) e a Embrapa Hortaliças, Seminis Vegetable Seeds, Rogers Seeds e Agroflora/Sakata Sudamerica pelo fornecimento das sementes utilizadas neste trabalho.

\section{REFERÊNCIAS}

BRUTON BD. Crater rot. 1996 In: ZITTER TA; HOPKINS DL; THOMAS CE (eds). Compendium of cucurbit diseases. St. Paul: APS Press. p. 49-50.

BRUTON BD. 1998. Soilborne diseases in cucurbitaceae: pathogen virulence and host resistance. In: MCCREIGHT J (ed). Cucurbitaceae '98. Alexandria: International Society of Horticultural Science. p. 143-166.

COSTA ND; SILVA HR. 2002. Cultivares. In: SILVA HR; COSTA ND (eds). Melão produção. Brasília: Embrapa Informação Tecnológica. Frutas do Brasil, 33. p. 29-34.

DOMSCH KW; GAMS W; ANDERSON T-H. 1980. Compendium of soil fungi. London: Academic Press v. 1. 859p.

FITTON M; HOLLIDAY P. 1983. Myrothecium roridum. Bakeham Lane: CABI Bioscience, $3 \mathrm{p}$.
(IMI Descriptions of Fungi and Bacteria, 253). FNP. 2006. Agrianual. 2006 -anuário da agricultura brasileira. São Paulo: Instituto FNP. 504p.

IBRAF. 2006. Informação e tecnologia a serviço da fruticultura. São Paulo: Instituto Brasileiro de Frutas, 2006. Disponível em http://www.ibraf.org.br/ x-es/pdf/CEBFF_2004_2005.pdf. Acessado em cinco de maio de 2006.

KUTI JO; NG TJ; BEAN GA. 1987. Reactions of muskmelon cultigens to Myrothecium roridum. Hortscience 22: 635-637.

LIMA GSA; OLIVEIRA SMA; BEZERRA NETO E; MENEZES M. 1997. Reação de cultivares de melão a isolados de Myrothecium roridum. Summa Phytopathologica 23: 135-139.

MCKINNEY HH. 1923. Influence of soil temperature and moisture on infection of wheat seedlings by Helminthosporium sativum. Journal of Agricultural Research 26: 195-218.

NEGREIROS MZ; COSTA FA; MEDEIROS JF; LEITÃO MMVBR; BEZERRA NETO F; SOBRINHO JE. 2005. Rendimento e qualidade do melão sob lâminas de irrigação e cobertura do solo com filmes de polietileno de diferentes cores. Horticultura Brasileira 23: 773-779.

NORONHA MA; MICHEREFF SJ. 2006. Influência dos métodos de inoculação no desenvolvimento de cancros causados por Myrothecium roridum em plantas de meloeiro. In: CONGRESSO BRASILEIRO DE FITOPATOLOGIA, 39. Fitopatologia Brasileira 31: S280 (Resumo).

NORONHA MA; MICHREFF SJ; MOREIRA PAA; XAVIER FILHA MS; SALES JUNIOR R; MIZUBUTI ESG. 2006. Variabilidade de isolados de Myrothecium roridum provenientes de meloeiro cultivado no estado do Rio Grande do Norte. In: CONGRESSO BRASILEIRO DE FITOPATOLOGIA, 39. Fitopatologia Brasileira 31: S281 (Resumo).

NUNES GHS; SANTOS JÚNIOR JJ; ANDRADE FV; BEZERRA NETO F; ALMEIDA AHB; MEDEIROS DC. 2004. Aspectos produtivos e de qualidade de híbridos de melão cultivados no agropolo Mossoró-Assu. Horticultura Brasileira 22: 744-747.

SILVADMW; PEREIRA GFA; OLIVEIRA SMA; MENEZES M. 1993. Reação de genótipos de melão a Myrothecium roridum. Resumos. Summa Phytopathologica 19: 42.

SILVA DMW; MENEZES M; OLIVEIRA SMA; PEREIRAGF. 1996. Ocorrência de Myrothecium roridum em melão em Mossoró, Rio Grande do Norte. Fitopatologia Brasileira 21: 519.

VIANA FMP; SANTOS AA; FREIRE FCO; CARDOSO JE; VIDAL JC. 2001. Recomendações para o controle das principais doenças que afetam a cultura do melão na Região Nordeste. Fortaleza: Embrapa Agroindústria Tropical. 6p. (Embrapa Agroindústria Tropical. Circular técnica, 12). 